\title{
EPIDEMIOLOGICAL STUDIES OF HYDATIDOSIS AMONG SLAUGHTERED SHEEP AND HUMAN IN TAIF, SAUDI ARABIA
}

\author{
JAMILA S. AL-MALKI and NABILA S. DEGHEIDY \\ Biology Department Science Collge, Tiaf University, KSA. \\ Email: degheidyn@yahoo.com
}

\section{ABSTRACT}

Received at:11/9/2013

A total of 85201 sheep (71001 local bred and 14200 imported bred) were slaughtered and examined for hydatosis during the period 2010-2012, at Al Taif, Saudi Arabia. The obtained data indicated that 10957 of sheep were suffering from hydatosis with $9.60 \%$ for local bred and $29.15 \%$ for imported bred. In Accepted: 7/10/2013 human, the first case for hydatosis in Taif was recorded in one female twenty four years old, well educated suffering from gastrointestinal tract-related symptoms, fatiguability and chronic ill-health. The patient had no contact to dogs or animals and live in Taif governorate. The medical records department provided detected cystic echinococcosis with different Size in spleen.

Keyword: Echinococcus granulosus, cystic echinococcosis, hydatidosis, Human hydatidosis, hydatidosis in Taif.

\section{INTRODUCTION}

Hydatid disease (echinococcosis) is a zoonotic infection disease of humans caused by Echinococcus granulosus. The disease poses an important public health problem in many areas of the world, particularly among populations that practice sheep husbandry Awatif Alam, (1999). The prevalence of the disease is reported to be high in Middle Eastern countries, including Saudi Arabia, due to the presence of sheep and dogs living in close contact with humans, especially among the Bedouins (Jastaniah 1997). E. granulosus is present virtually worldwide since there are very few countries that are considered to be completely free of $E$. granulosus (Budke et al.,2010). An important fact to keep in mind is that the areas of the world where there is a high incidence of infection by $E$. granulosus often coincide with rural, grazing areas where dogs are able to ingest organs from infected animals. All disease-causing species of Echinococcus are transmitted to intermediate hosts via the ingestion of eggs and are transmitted to definitive hosts by means of eating infected, cyst-containing organs. Humans are accidental intermediate hosts that become infected by handling soil, dirt or animal hair that contains eggs (Eckert, 2010). The incubation period for all species of Echinococcus can be months to years or even decades (Kemp et al., 2010). It largely depends on the location of the cyst in the body and how fast the cyst is growing (Eckert et al., 2010).

Shalaby et al. 2011 stated that, a total numbers of 2470 sheep was examind during post - mortum inspection at Taif abattoir for the presence of hydatic cyste. The prevalence of hydatidosis averaged 9.25, 4.58 and $0.43 \%$ among Turkish sheep, Sudancese sheep and Australian sheep respectively. Studies of the disease in the Kingdom of Saudi Arabia have shown multi-organ involvement, including the heart (Budke, Christine et al., 2010). A relatively high frequency of pulmonary hydatid disease has been reported, presumably because of airborne spread, with the lungs acting as the first filter instead of the liver (Jastaniah 1997). Most published studies on hydatid disease addressclinical and/or management experiences, most which are comparable in many instances (Awatif Alam, 1999). Echinococcosis, which is often referred to as hydatid disease or echinococcal disease, is a parasitic disease that affects both humans and other mammals, such as sheep, dogs, rodents and horses - Berger and Marr (2006). There are three different forms of echinococcosis found in humans, each of which is caused by the larval stages of different species of the tapeworm of genus Echinococcus. The first of the three and also the most common form found in humans is cystic echinococcosis (also known as unilocularechinococcosis), which is caused byEchinococcus granulosus. E. granulosus is present virtually worldwide since there are very few countries that are considered to be completely free of E. granulosus Sréter et al. (2010). An important fact to keep in mind is that the areas of the world where there is a high incidence of infection by E. granulosus often coincide with rural, grazing areas where dogs are able to ingest organs from infected animals. In the human manifestation of the disease, E. granulosus, E. multilocularis, E. oligarthus and $E$. vogeli are localized in the liver (in $75 \%$ of cases), the lungs (in $5-15 \%$ of cases) and other organs in the body such as the spleen, brain, heart and kidneys (in $10-20 \%$ of cases). In the patients who are infected with E. granulosus and therefore have cystic echinococcosis, the disease develops as a slowgrowing mass in the body. These slow-growing 
masses, often called cysts, are also found in patients that are infected with alveolar and polycystic echinococcosis.

All disease-causing species of Echinococcus are transmitted to intermediate hosts via the ingestion of eggs and are transmitted to definitive hosts by means of eating infected, cyst-containing organs. Humans are accidental intermediate hosts that become infected by close contact with dogs and poor personal hygienic practices. The most important source of human infection can be vegetables and water contaminated with dogs feces. Coprophagic flies can act as mechanical vectors of the eggs (Pan American Health organization, 2006 and Romich, 2006).

The hydatid tapeworm (Echinococcus granulosis) is one of seven tapeworms known to infect dogs in Australia. The lifecycle of this parasite can involve a number of animals, including humans, but the most important species involved are sheep, kangaroos and dogs. Concerning hydatid disease in human Marguerite-Hawkins (1998) reported that a 60 year old woman from Saudi Arabia presented for evaluation of a palpable abdominal mass in the right upper quadrant. Abdominal films revealed solid and cystic lesion in the right hepatic lobe and Serology for Echinococcus was positive.

A descriptive study of patients suffering from hydatid disease between 1988 and 1997 was carried out at a major specialized hospital. This study showed that the disease was more common among illiterate population, house wives and among agricultural workers and shepherds. In addition, there was a high frequency among those coming in contact with dogs (Abu-Eshy and Elamin 1999).

Cystic echinococcosis (CE) is an important parasitic disease that constitutes a major public health problem in Yeman (Nagat 2012). Abo-Ayash (1998) reported that, among all the cases of hydatid disease seen in an 8-year period at Asir Central Hospital, Abha, Saudi Arabia seven cases are reported. One patient had a brain hydatid cyst. The second patient had pericardial hydatidosis. The third female had multiple pelvic hydatid cysts The fourth case was a huge single hydatid cyst filling the whole abdominal cavity. The fifth case had liver hydatid cysts. The sixth case had diaphragm hydatid cysts. The last patient presented with a hydatid cyst of the right thigh.

Therefore, the present study aimed to determine the prevalence of hydatidosis among sheep and human in Taif, Saudi Arabia.

\section{MATERIALS and METHODS}

\section{Sheep Samples}

The present study was conducted at Al-Taif slaughtered house, KSA, from January 2010 to December 2012. The study populations were sheep of different age, body conditions, local and imported from countries for the purpose of meat production. A cross-sectional study was used to determine the prevalence of hydatidosis in 71,001 of local sheep and 14200 of different species of imported sheep were collected to determine the prevalence of hydatidosis. Routine post mortem inspection of the carcasses were carefully inspected for each animal was carried out to check the presence of hydatid cysts. The organs of infected animals were sent to research laboratory at the Faculty of Science, Taif University for further examination. Infected organs were processed as described by (Nagat et al., 2012).

\section{Case history of hydatidosis in human}

Clinical Features: One female patient (24) years old, well educated suffering from gastrointestinal tractrelated symptoms, pain in the upper abdominal region, itching, nausea, epigastric pain general malaise, spleen enlargement, fatiguability, high eosinophilia was present and chronic ill-health. The patient had no contact to dogs or animals and live in Taif governorate. She admitted to King Abd All Aziz specialized hospital in Taif, Saudia. She is subjecting to full clinical, parasitological and serodiagnostic examination.

The medical records department provided a computer-generated print-out of the patients admitted with a diagnosis of Echinococcus granulosus infection. Data compiled for the patient included demographic information (age, sex, education, occupation, nationality and area of residence). A past and present history of intimate contact with dogs, presenting symptoms, and clinical findings, was also considered.

The diagnosis was confirmed by serological tests, including indirect hemagglutination test (IHA), Casoni skin test and radiological tests, such as plain radiography, ultra-sound and computerized tomography. The diagnosis was based on the characteristic ultrasonic findings, calcification of the cyst wall and on endoscopic findings. Specimens obtained at surgery were subjected to histology for confirmation of the diagnosis. All the patient investigation were done in King Abd All Aziz specialized hospital laboratories in Taif.

Data Analysis: The data which were recorded during the study period were entered into Microsoft excel sheet. Data were summarized and analyzed using SPSS version 16 computer program. Data were analyzed using Epi Info version 6 statistical software (Coulombier et al., 2001) and for further compared using Chi-square test at critical probability of $\mathrm{p}<0.05$.

\section{RESULTS}

Table (1) show: The prevalence of hydatidosis in slaughtered animals in Taif abattoir, KSA among 
sheep. It showed that the total of 71.001 local sheep was slaughtered in period (2010-2012) and 6818 were suffering from hydatidosis. A significantly $(\mathrm{p}<0.05)$ higher prevalence of hydatidosis was recorded in sheep $(9.60 \%)$. Also showed that the percentage of hydatidosis among sheep during 2010 -2011 and 2012 was $7.58,7.11$ and 16.02 respectively.

Table 1: Prevalence of hydatidosis in slaughtered local bread sheep during the periods 2010 - 2012 in Taif abattoir, KSA.

\begin{tabular}{ccccc}
\hline Year & Species & $\begin{array}{c}\text { Number of animals } \\
\text { slaughtered }\end{array}$ & $\begin{array}{c}\text { Number of } \\
\text { infested animals }\end{array}$ & $\begin{array}{c}\text { Percentage } \\
\%\end{array}$ \\
\hline 2010 & Sheep & 14501 & 1086 & 7.58 \\
\hline 2011 & Sheep & 20266 & 1440 & 16.02 \\
\hline 2012 & Sheep & 26784 & 4292 & 9.60 \\
\hline Total & Sheep & 71,001 & 6818 & \\
\hline
\end{tabular}

Table 2: Prevalence of hydatidosis in slaughtered imported bread sheep during the periods 2010 - 2012 in Taif abattoir, KSA.

\begin{tabular}{|c|c|c|c|c|}
\hline Year & Species & $\begin{array}{l}\text { Number of animals } \\
\text { slaughtered }\end{array}$ & $\begin{array}{c}\text { Number of } \\
\text { infested animals }\end{array}$ & $\begin{array}{c}\text { Percentage } \\
\%\end{array}$ \\
\hline 2010 till 2012 & Sheep & 14200 & 4139 & 29,15 \\
\hline
\end{tabular}

Concerning hydatidosis in human Table 3: showed summary of human hydatidosis reported in Taif, Kingdom of Saudi Arabia 2013. After full investigation, the female patient had hydatid disease of the spleen.

Table 3: Summary of human hydatidosis reported in Taif, Kingdom of Saudi Arabia 2013.

\begin{tabular}{cc}
\hline $\begin{array}{c}\text { Number of } \\
\text { patient }\end{array}$ & One \\
\hline Age & 24 year \\
\hline $\begin{array}{c}\text { Sex and } \\
\text { education }\end{array}$ & Female \\
\hline Natunality & Suadi Arabia \\
\hline $\begin{array}{c}\text { History of abroad } \\
\text { travel }\end{array}$ & Absent \\
\hline Involved organ & Spleen \\
\hline Symptoms & gastrointestinal tract-related symptoms spleen enlargement chronic ill-health $(5$ years) \\
\hline Reference & King Abd All Azizs pecialized hospital in Taif \\
\hline Diagnosis & Echinococcus granulosus infection. (Hydatosis ) \\
\hline Treatment & Spleenoctomy and medical treatment \\
\hline
\end{tabular}




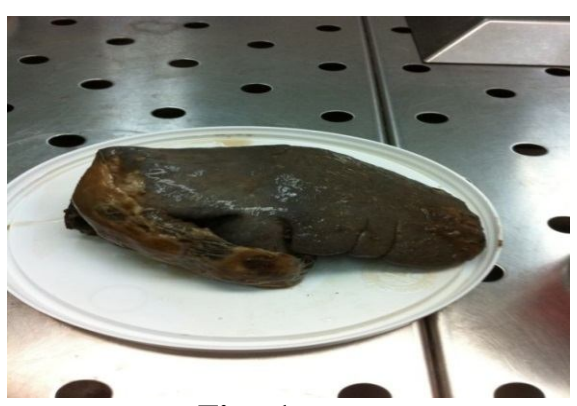

Fig : 1

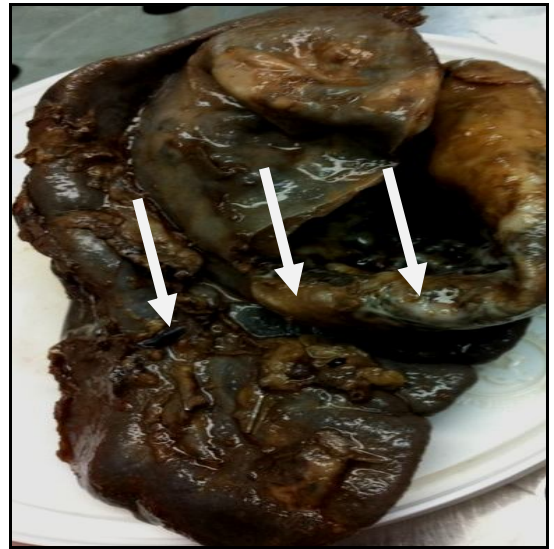

Fig : 3

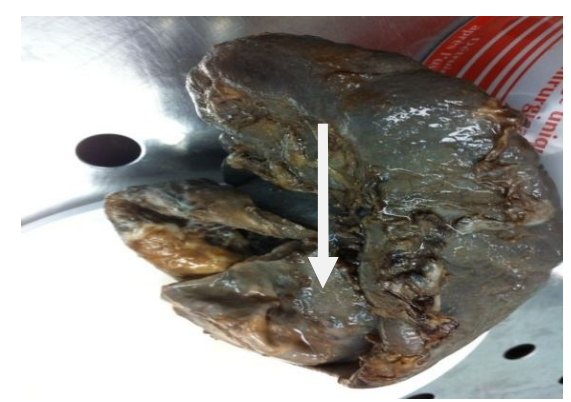

Fig : 2

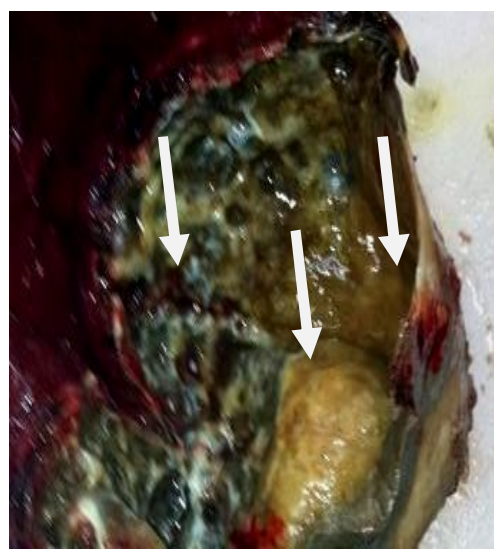

Fig : 4

Figure 1 showed: spleen from the patient post spleenoctomy operation.

Figure 2,3 and 4 showed appearance of a typical cyst at remove from the patient, the outer of the cyst was necrosed, present of hemorrhage, fibrosis and inflammation.

Treatment: Surgery is generally considered the treatment of choice.

Surgery is indicated for non-complicated cysts in patients who are in good general Condition (Eckert et al., 2010). In the case under study spleenoctomy was performed and indications for medical treatment

\section{DISCUSSION}

The total infections rate of hydatidosis in the present study in local sheep $(9.60 \%)$ was lower compared with $(13.51 \%)$ in Taif governorate abattoir (Shalaby et al., 2011). While the prevalence of hydatidosis in imported sheep $(29,15 \%)$ in the present study. In alHasa in Suadi Arabia Echinococcus granuolosis in stray dogs was around $15.60 \%$ and a massive infection (500.000) worms was observed in one case (Kawasmeh et al., 1984). Shalaby et al. (2011) recorded that in Jedda high percent of infection with Echinococcus granuolosis in livestock slaughtered area, could result in the spread of this zoonotic disease to local stray dogs. Consequently, human and animals infection with intermediate stage (hydatide cycte) may aris. Human hydatidosis has been recorded in various other parts of kingdom (Kawasmeh et al., 1984). In a work on cystic echinococcosis in three areas in Saudi Arabia in camels, cattle, sheep and goats, the prevalence of the infection was 32.85, 8.28, 12.61 and $6.56 \%$ respectively (Nasher1990). These results showed higher than our finding in this study. However, the prevalence of E. granulosus (hydatidosis) in livestock slaughtered in Jeddah area was (13.10), could result in the spread of this zoonotic infection to local stray dogs and cats. Consequently, human and animal infection with intermediate stage (hydatid cyst) may arise (Shalaby et al., 2011).

Human hydatid disease has been reported for the first time in Taif in 24 years old Saudi Arabia female live in Taif (according to the report of Health Administration in Taif, Suadi Arabia for 20 years ago), although she had no direct contact with pet animals or slaughtered houses as well as she well educated. Cystic echinococcosis should be suspected in patients with cystic lesions, particularly those living or coming from endemic areas, or in direct contact with definitive hosts and intermediate hosts. Definitive hosts are normally carnivores such as dogs, while intermediate hosts are usually herbivores such as sheep and cattle. Humans function as accidental hosts, because they are usually a 'dead end' for the parasitic infection cycle. Results of this study may agree with Awatif Alam1999 showed that hydatid disease is predominant disease of young Saudi adults and has a low mortality and those that appear to be at 
risk are house wifes. Also E. granulosus transmitted to intermediate hosts via the ingestion of eggs and are transmitted to definitive hosts by means of eating infected, cyst-containing organs. Humans are accidental intermediate hosts that become infected by handling soil, dirt or animal hair that contains eggs (Ammann and Eckert 1995).

From discussion with the patient Case under experiment, said that she usually consumed processed meat and junky food. The source of infection for her may be due to eating contaminated raw vegetables with junky food. In conclusion, this study addressed the need to evaluate and control the parasitic pressure of Echinococcus granulosus in humans and sheep in endemic foci.

This study revealed higher prevalence of Echinococcus granulosus (hydatidosis) among imported livestock animals in Taif area. Therefore should be quarantined all imported animals upon arrival, for general inspection, drenching, spraying and medication. Moreover, they should be segregated during fattening or grazing from indigenous livestock. Slaughtering livestock outside abattoirs without veterinary supervision should also be avoided. Prevention of hydatid disease includes also worming infected dogs, burning infected carcasses, and careful hand-washing after contact with potentially infected dogs. Preventive strategies would, therefore, not only involve health education, reduced contacts with dogs and sheep, with effective disposal of their wastes but also avoid consume processed meat and junky food. Prevent all pets to enter the slaughter houses or eating cystic echinococcosis coming out from slaughtered cattle (Belen Otero and Paul Torgerson 2013).

\section{REFERENCES}

Abu-Eshy, S.A. (1998): Some rare presentations of hydatid cyst (Echinococcus granulosus). J R Coll Surg Edinb. Oct; 43(5): 347-52.

Abu-Eshy, S.A. and Elamin Ali, M. (1999): Hydatid cyst associated with pregnancy: A case report and review of the literature. AnnSaudi Med. 19: $130-131$.

Ammann, R. and Eckert, J. (1995): Clinical diagnosis and treatment of echinococcosis in humans. In: Thompson R C A, Lymbery AJ (eds) Echinococcus and hydatid disease. C A B International, Wallingford; 411-463.

Awatif A. Alam (1999): Epidemiology of hydatid disease in riyadh. Annals of Saudi Medicine, Vol 19, No 5.

Belen Otero-Abad and Paul R. Torgerson (2013): A Systematic Review of the Epidemiology of Echinococcosis in Domestic and Wild Animals. Vetsuisse-Faculty, University of Zurich, Section for Veterinary Epidemiology,
Zurich, Switzer land. Open access available online.

Berger, S.A. and Marr, J.S. (2006): Human Parasitic Diseases Sourcebook. Jones and Bartlett Publishers: Sudbury, Massachusetts.

Budke Christine M.; Peter Deplazes, and Paul R. Torgerson (2010): "Global Socioeconomic Impact of Cystic Echinococcosis:” Emerging Infectious Disease Web. 15 February.

Coulombier, D.R.; Fagan, S.L. and Hathcock and C. Smith (2001): Epi Info 6 Version 6.04 A. Word proccessing, database and Statistical Program for Public Health. Centers for Disease Control and Prevention, Atlanta, USA.

Eckert, Johannes and Peter Deplazes. (2010): "Biological, Epidemiological, and Clinical Aspects of Echinococcosis, a Zoonosis of Increasing Concern." Clinical Microbiology Reviews 17.1 107-135. Web. 5 February.

Jastaniah, S.; Malatani, T.S.; Abu-Eshy, S.; Al Shehry, M.; Hamdi, J.; Al Naami, M.; Biomy, A. and Ghatani, S.S. (1997): Hydatid cyst disease (Echinococcu granulosus) Experience at Asir central hospital, Saudi J Gastroenterol; 3: 140-143.

Kawasmeh, A.; Cheema, A.H. and Shigidi, M.T. (1984): prevalence of E.granulosus । hydatidosis in stray dogs and slaughtered animals in Al-Hasaregion, Seventh Symposium on the Biological aspects of Saudi Arabia, PP: 79-80.

Kemp, Charles, and Amy Roberts (2010): Echinococcosis (Hydatid Disease)." Wiley InterScience Logo Journal of the American Academy 2001 zof Nurse Practitioners 346-47. Web. 21 February 2010.

Marguerite-Hawkins (1998): The Johns Hopkin Smicro Biology new sletter .vol. 17, no. 19.

Nagat, A.; Muqbil, Al-salami, O.M. and Arabh, H.A. (2012): Prevalence of UnilocularHydatidosis in Slaughtered Animals in Aden GovernorateYemen. JJBS Volume 5, Number 2, Pages 121-124.

Nasher, A. (1990): Parasiles of livestock in Asir province, southwestern Saudia Arabia, Vetrinary Parasitology, 37 (3-4): 297 -300.p \& Distribut.

Pan American Health Organization (2006): Zoonoses and communicable diseases common to man and animals. Pages 193 - 196. A.I.T.B.S. publishers \& Distributors (Regd.), J. 516, Krishan Nagar, Near Hansroy School, Delhi 110051, India.

"Parasite Image Library: Echinococcosis." (2010): DPDx. CDC, Web. 20 February <http:// www.dpd.cdc.gov/dpdx/HTML/ImageLibrary/ Echinococcosis_il. htm.

Romich, J.A. (2008): Understanding zoonotic disease. PP 398 - 404. Thomson Delmer. Delmer Park, NY $1206-2919$. 
Shalaby M. IsmaiL; Banaja, A.A. and Manal, M. Gamgom (2011): Comparative study on the prevalence of some parasites in animals slaughtered at new Taif abattoir. Global Veterinaria 6 (3)295-299.
Sréter, Tamás, ZoltánSzéll, ZsuzsaEgyed, and IstvánVarga. Echinococcus multilocularis (2010): an Emerging Pathogen in Hungary and Central Eastern Europe. Emerging Infectious Disease (2003). Web. 20 February.

\section{دراسة وبائية عن داء المشوكات الكيسي في ذبائح الأغنام والإنسان في الطائف، المملكة العربية السعودية}

\section{جمبيلة المالكي ، نبيلة دغيلى}

Email: degheidyn@yahoo.com

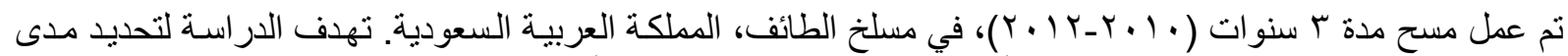

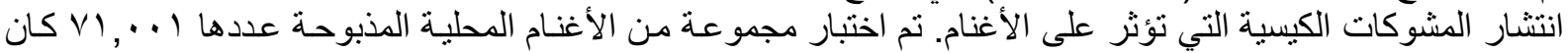

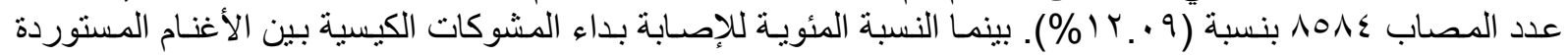

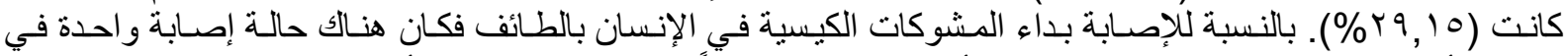

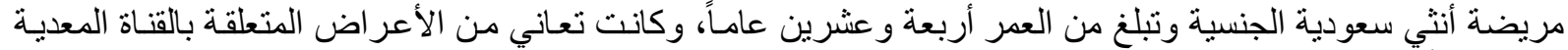

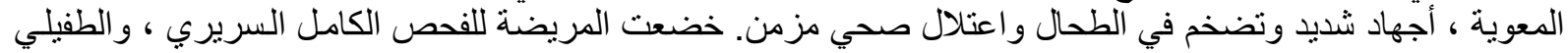
و التحاليل الطبية المتخصصة. تبين من الفحص إصـابة المريضة بداء المشوكات الكيسي في الطحال. وتعتبر هي الحالة الكية الأولي في الطائف، المملكة العربية السعودية. 